\title{
Characteristics of Paleozoic clastic reservoirs and the relationship with hydrocarbon accumulation in the Tazhong area of the Tarim Basin, west China
}

\author{
Wang Zhaoming ${ }^{1}$, Liu Luofu ${ }^{2,}{ }^{3 *}$, Yang Haijun ${ }^{1}$, Wang Weili ${ }^{2,}$, Zhang \\ Baoshou $^{1}$ and Han Jianfa ${ }^{1}$ \\ ${ }^{1}$ PetroChina Tarim Oilfield Company, Korla, Xinjiang 841000, China \\ ${ }^{2}$ State Key Laboratory of Petroleum Resources and Prospecting, China University of Petroleum, Beijing 102249, China \\ ${ }^{3}$ Basin and Reservoir Research Center, China University of Petroleum, Beijing 102249, China \\ (C) China University of Petroleum (Beijing) and Springer-Verlag Berlin Heidelberg 2010
}

\begin{abstract}
In order to predict favorable exploration areas of the Paleozoic, Carboniferous and Silurian clastic reservoirs in the Tazhong area of the Tarim Basin, west China, we studied the basic characteristics of Paleozoic clastic reservoirs in the Tazhong area based on a lot of data. Several issues about the hydrocarbon accumulation related to the reservoirs were also discussed. The results were concluded that: the high-value areas of the porosity and permeability of clastic reservoirs were located in the southeast of the Tazhong area; the content of cement (carbonate cement in particular) was the main factor controlling the porosity and permeability of clastic reservoirs; the hydrocarbon distributions of Carboniferous and Silurian clastic reservoirs were closely related to the porosity and permeability; the favorable hydrocarbon accumulation areas of the two sets of strata were located in the southeast of this area, especially in the updip pinch-out area.
\end{abstract}

Key words: Clastic reservoir, Carboniferous, Silurian, Paleozoic, hydrocarbon accumulation, Tazhong area, Tarim Basin

\section{Introduction}

In the Tazhong area of the Tarim Basin, the Paleozoic clastic rock is the major hydrocarbon-producing stratum, and plays a vital role in the hydrocarbon exploration and development of the basin (Liu et al, 1995; Jia et al, 2006; Sun et al, 2005; Liu et al, 2004). Up to now, many scholars have done detailed research on Paleozoic reservoirs in this area (Shen et al, 2006; Li et al, 2000; Wang and Lü, 2004; Dai et al, 2001; Chen et al, 1999; Liu et al, 2008) and have obtained fruitful results. A lot of work has been carried out especially on the characteristics of a single reservoir in the well blocks. However, research on the comparison among different reservoirs and the changes of reservoir characteristics in the plane is relatively weak. In this study, based on a large amount of data (such as rock-plug porosity and permeability of reservoirs in the single-wells, planar sedimentary facies, fracture distribution, thin section analysis and reservoir characteristics), we investigated the characteristics of Carboniferous and Silurian reservoirs in the Tazhong area macroscopically, compared the characteristics among different systems, analyzed the changes of porosity

*Corresponding author. email: liulf@cup.edu.cn Received September 2, 2009 and permeability in different areas, discussed the main factors controlling porosity and permeability of reservoirs, and searched for the relationship between reservoir characteristics and hydrocarbon distribution, expecting to provide basic information for the next step of exploration and development.

\section{Basic characteristics of Paleozoic clastic reservoirs in the Tazhong area}

The Paleozoic clastic reservoirs in the Tazhong area of the Tarim Basin are mainly distributed in the Carboniferous and Silurian strata which are currently the hydrocarbon-producing strata and are also the next exploration targets in this area (Table 1).

\subsection{Carboniferous Donghe sandstone}

The Donghe sandstone (i.e., the oil group $\mathrm{C}_{\mathrm{III}}$ ), widely distributed in the Tazhong area (Zhong et al, 2004; Gu, 1996; Zhu et al, 2004; Wu et al, 2006), is generally buried at a shallow depth of 3,500-3,700 m (Gu et al, 2006), and contains lithic quartz sandstone, feldspar-lithic quartz sandstone and lithic sandstone, with a small amount of quartz sandstone. On the whole, the content of rock debris is high (Fig. 1). That of quartz is $65 \%$ in general, mostly over $70 \%$ with higher compositional maturity. Because of the various sedimentary 
Table 1 Division of the Silurian and Carboniferous strata in the Tazhong area of the Tarim Basin

\begin{tabular}{|c|c|c|c|}
\hline \multicolumn{3}{|c|}{ Stratigraphic system } & \multirow{2}{*}{ Lithologic characteristics } \\
\hline System & Formation & Member & \\
\hline \multirow{8}{*}{ Carboniferous } & Xiaohaizi & Limestone & Micrite mixed with mudstone and silty mudstone \\
\hline & \multirow{4}{*}{ Kalashayi } & Sand shale & $\begin{array}{l}\text { Mudstone interbedded with fine sandstone, pebbled } \\
\text { medium sandstone and silty mudstone }\end{array}$ \\
\hline & & Upper mudstone & Mudstone mixed with silty mudstone \\
\hline & & Standard limestone & Micrite \\
\hline & & Middle mudstone & Mudstone mixed with silty mudstone \\
\hline & \multirow{3}{*}{ Bachu } & Bioclastic limestone & Bioclastic limestone \\
\hline & & Lower mudstone & Thick layered mudstone \\
\hline & & Donghe sandstone & Fine sandstone mixed with medium sandstone \\
\hline Devonian & & & Brown-red mudstone mixed with silty mudstone \\
\hline \multirow{6}{*}{ Silurian } & Yimugantawu & Upper mudstone & Light brown mudstone \\
\hline & \multirow[t]{2}{*}{ Tataaiertage } & Sand shale & $\begin{array}{l}\text { Light gray fine sandstone interbedded with light green } \\
\text { and brown fine sandstone }\end{array}$ \\
\hline & & Red mudstone & Brown-red mudstone \\
\hline & \multirow{3}{*}{ Kepingtage } & $1^{\text {st }}$ upper submember & Fine sandstone mixed with bituminous fine sandstone \\
\hline & & $2^{\text {nd }}$ upper submember & Brown-red mudstone \\
\hline & & $3^{\text {rd }}$ upper submember & Bituminous fine sandstone mixed with fine sandstone \\
\hline
\end{tabular}

facies and the differences in porosity and permeability, generally the porosity is $3 \%-20 \%$ and the permeability is $(0.1-500) \times 10^{-3} \mu \mathrm{m}^{2}$ (Fig. 2). There is a relatively good linear relationship between porosity and permeability. From Fig. 3, there are two high-value areas of porosity and permeability, respectively. Those of porosity are $0-8 \%$ and $15 \%-20 \%$, and those of permeability are $0-3 \times 10^{-3} \mu^{2}$ and over $100 \times 10^{-3} \mu \mathrm{m}^{2}$. In the Donghe sandstone reservoirs, the main porosity types are residual primary intergranular pores and intergranular dissolved pores (Fig. 4)

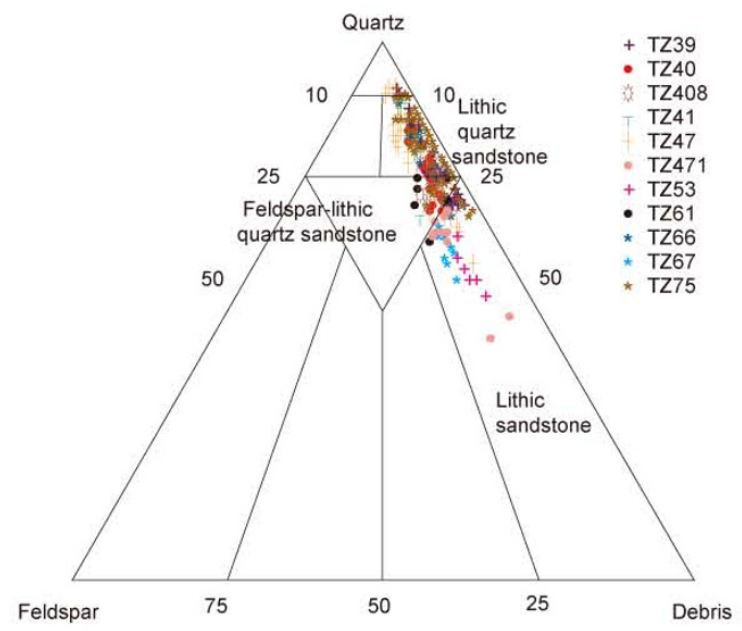

Fig. 1 Triangular diagram of the composition of the Carboniferous Donghe sandstone in the Tazhong area, Tarim Basin

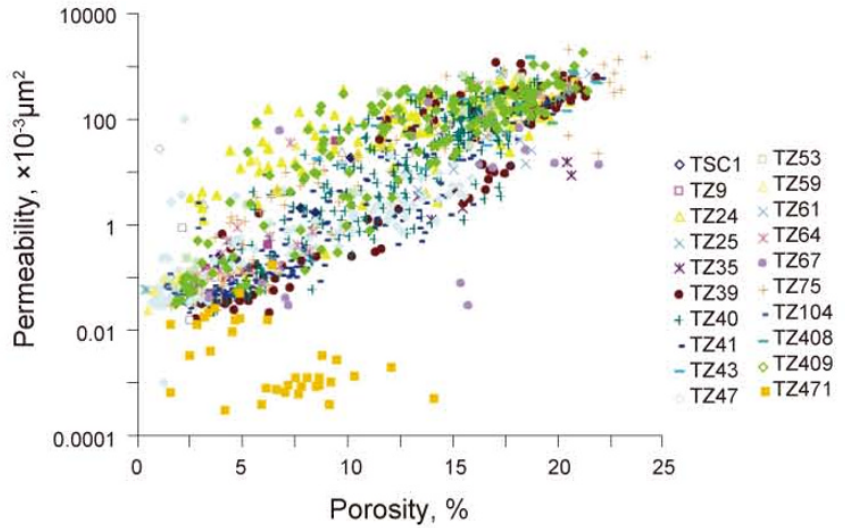

Fig. 2 Plot of porosity versus permeability of the Carboniferous Donghe sandstone in the Tazhong area, Tarim Basin

\subsection{Silurian}

The Silurian clastic reservoirs in the Tazhong area include the $1^{\text {st }}$ and $3^{\text {rd }}$ upper submembers of the Kepingtage Formation (Table 1). The latter has better reservoir porosity and permeability and hydrocarbon potential than the former.

The $1^{\text {st }}$ upper submember consists mainly of lithic sandstone, with a small amount of feldspar-lithic quartz sandstone and low compositional maturity (Fig. 5(a)). The quartz content is generally between $25 \%$ and $70 \%$, mostly about $50 \%$. There are large differences in porosity and permeability. The porosity is mainly between $3 \%$ and $18 \%$, 


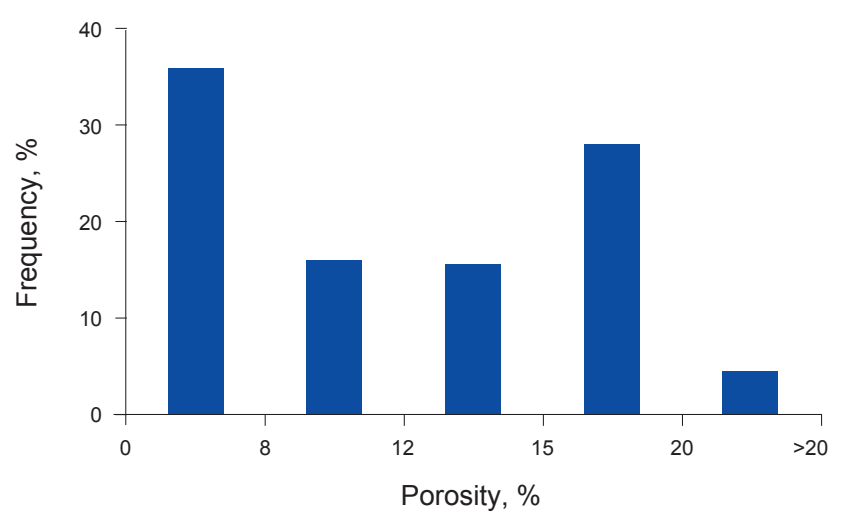

(a)

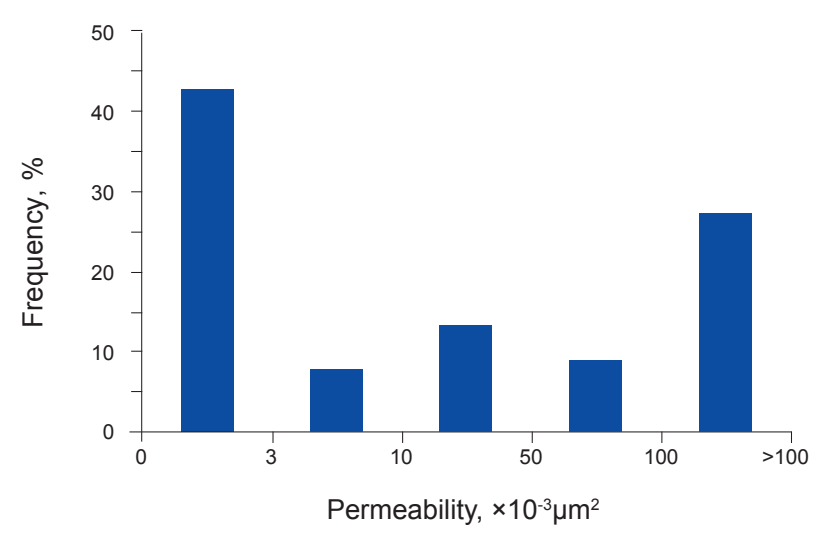

(b)

Fig. 3 Frequency distribution of porosity (a) and permeability (b) of the Carboniferous Donghe sandstone in the Tazhong area, Tarim Basin

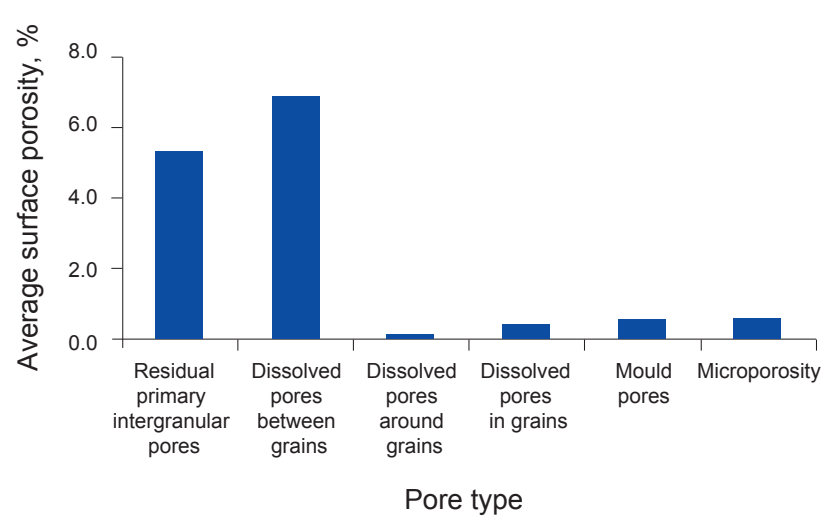

Fig. 4 Frequency distribution of porosity types of the Carboniferous Donghe sandstone reservoir in the Tazhong area, Tarim Basin

and the permeability is $(0.01-300) \times 10^{-3} \mu \mathrm{m}^{2}$ in general (Fig. $6(\mathrm{a})$ ). However, the values of porosity and permeability are mostly low, $0-9 \%$ and $0-2 \times 10^{-3} \mu \mathrm{m}^{2}$ respectively (Fig. 7), accounting for over $60 \%$ of the total number of samples, so the reservoir is poor. A relatively good linear relationship between porosity and permeability also exists (Fig. 6). The main pore types of the $1^{\text {st }}$ upper submember are also primary intergranular pores and intergranular dissolved pores (Fig. 8).

The $3^{\text {rd }}$ upper submember also consists mainly of lithic sandstone and a small portion of lithic quartz sandstone. Compared with the $1^{\text {st }}$ upper submember, it has a larger amount of feldspar-lithic quartz sandstone (Fig. 5(b)). Nevertheless, the sandstone maturity of the $3^{\text {rd }}$ upper submember is still relatively low and the quartz content is generally $25 \%-75 \%$. The porosity and permeability are also poor and their values are basically the same as those of the $1^{\text {st }}$ upper submember. They are also distributed mainly in low-value areas, and there are relatively large differences among different regions. Overall, the $3^{\text {rd }}$ upper submember is better than the $1^{\text {st }}$ upper submember (Fig. 7). A relatively good linear relationship between porosity and permeability also exists (Fig. 6). The main type of porosity of the $3^{\text {rd }}$ upper submember is primary intergranular, and intergranular dissolved porosity is less (Fig. 8).

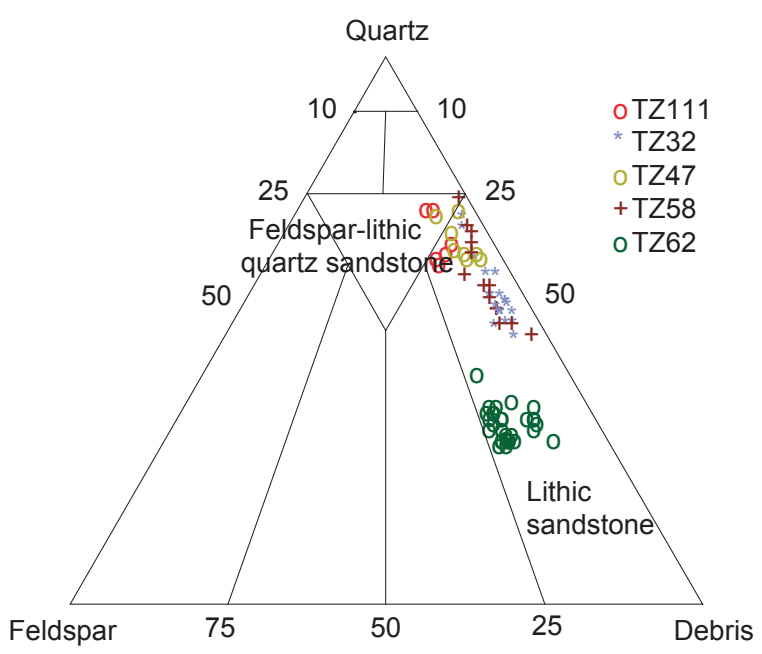

(a) The $1^{\text {st }}$ upper submember

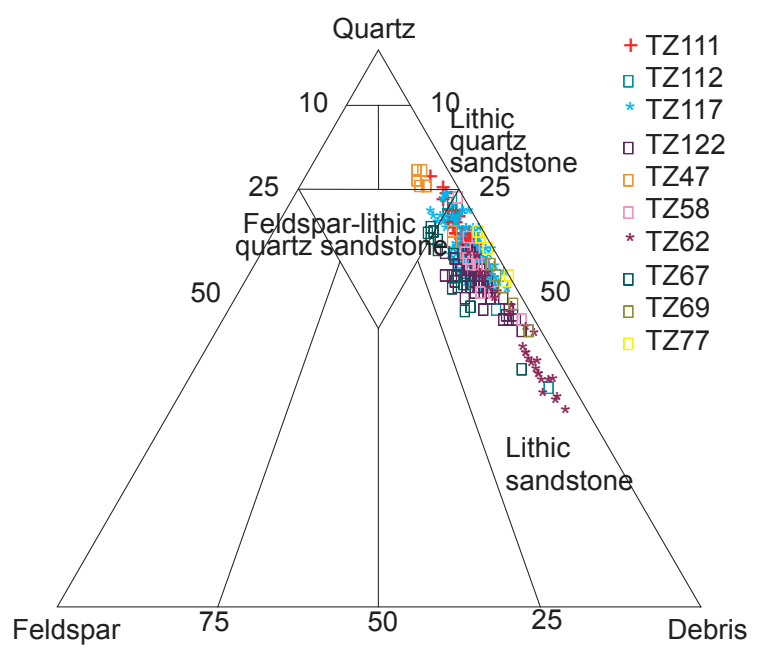

(b) The $3^{\text {rd }}$ upper submember

Fig. 5 Triangular diagram of the composition of the Silurian sandstone in the Tazhong area, Tarim Basin

From the comparison of reservoir properties, it can be concluded that the Carboniferous Donghe sandstone reservoir is better than the Silurian reservoir. 


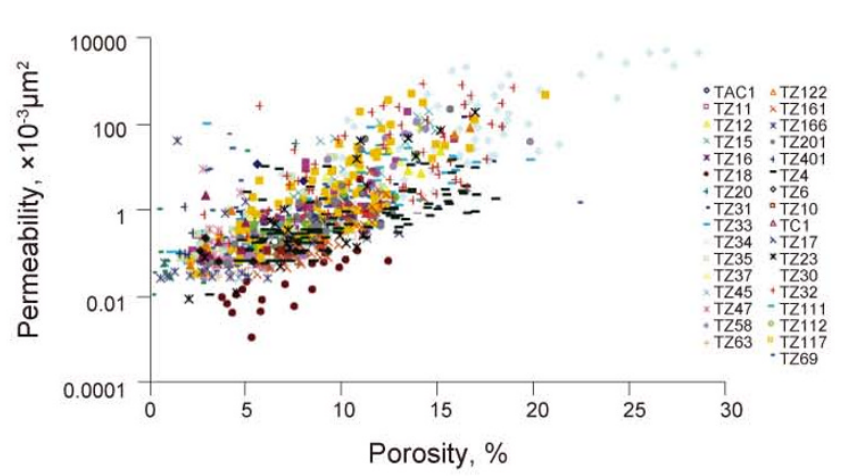

(a) The $1^{\text {st }}$ upper submember

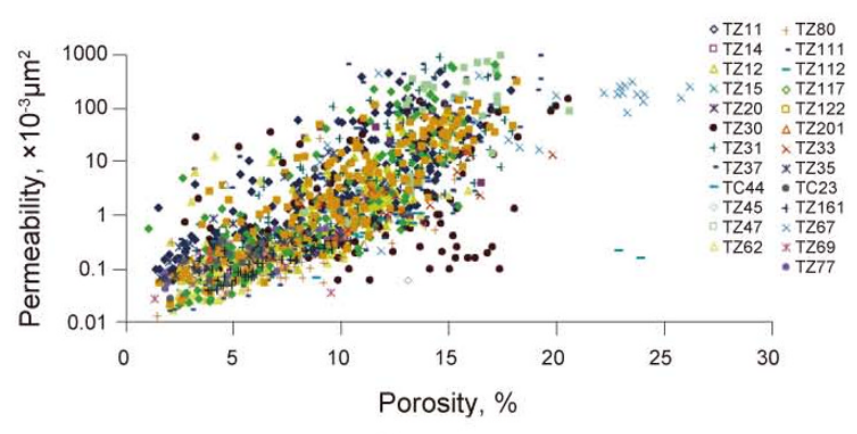

(b) The $3^{\text {rd }}$ upper submember

Fig. 6 Relationship between porosity and permeability of the Silurian reservoir in the Tazhong area, Tarim Basin

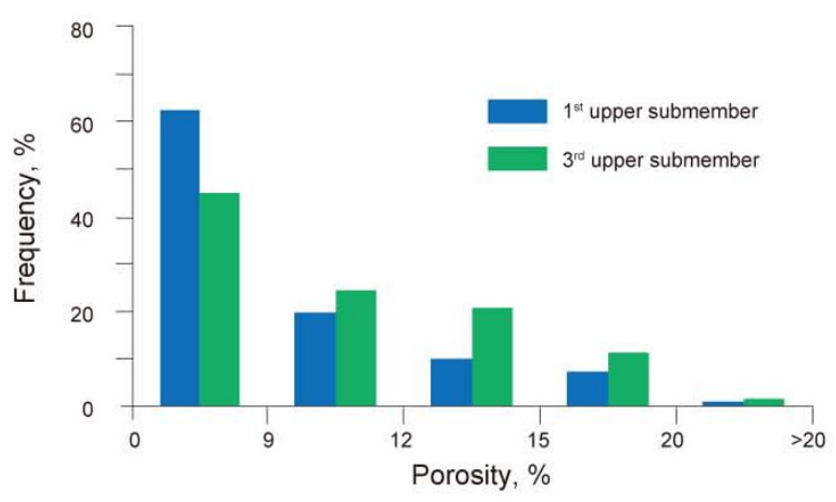

(a)

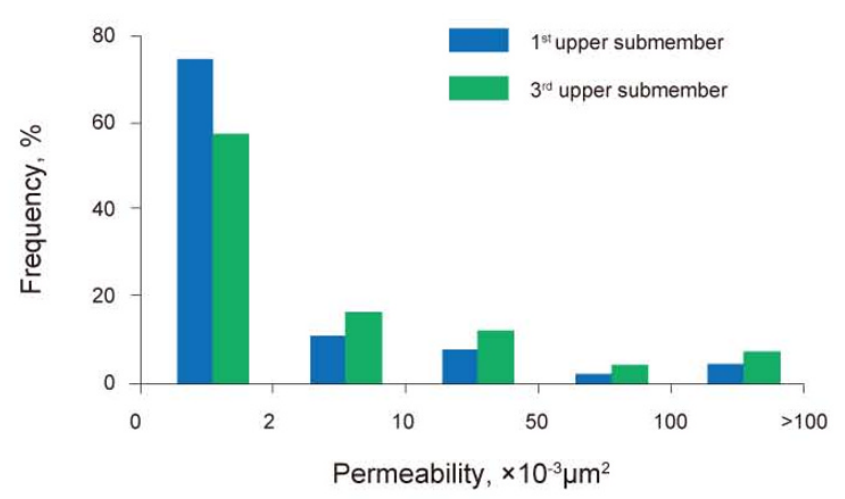

(b)

Fig. 7 Frequency distribution of porosity (a) and permeability(b) of the Silurian reservoir in the Tazhong area, Tarim Basin

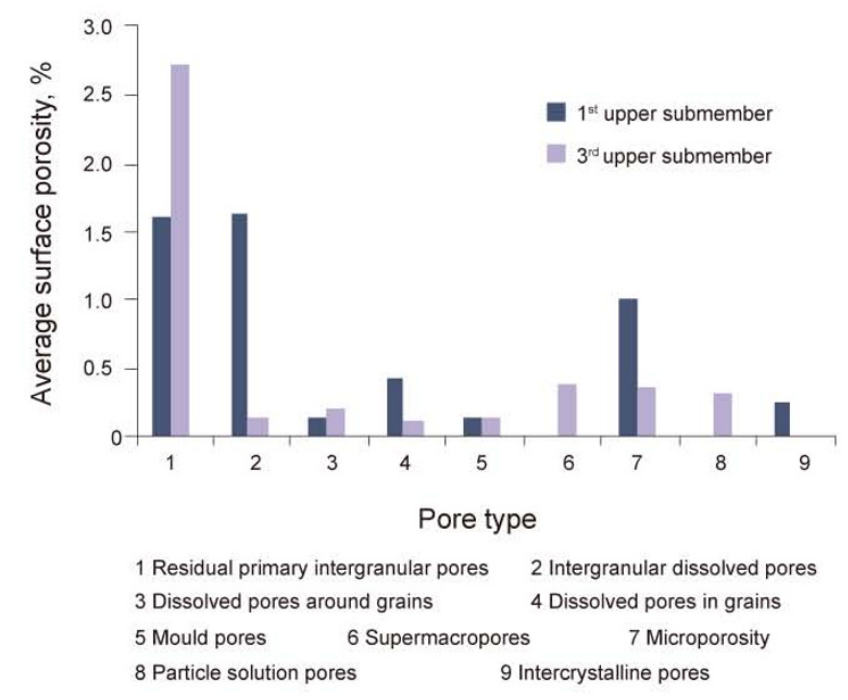

Fig. 8 Frequency distribution of porosity types of the Silurian reservoir in the Tazhong area, Tarim Basin

\section{The high-value areas of porosity and permeability of clastic reservoirs are located in the southeast of the Tazhong area}

On the basis of previous research, we drew the porosity and permeability distribution maps of the Carboniferous Donghe sandstone reservoir and the $1^{\text {st }}$ and $3^{\text {rd }}$ upper submember reservoirs of the Silurian Kepingtage Formation in the Tazhong area (Figs. 9, 10 and 11). From these figures we can see that the distribution of high-value areas of porosity is basically the same as that of permeability, and both of the high-value areas are located in the southeast of the study area. For the Carboniferous Donghe sandstone reservoir, in spite of relatively high porosity and permeability values in the TZ66-TZ54, TZ40-TZ20, TZ45-TZ35 and TZ46-TZ37 well blocks in the northwestern part, most of the high-value areas are located in the semi-oval shaped zone surrounded by wells TZ83, TZ50, TZ19, TZ61, TZ79, TC1, TZ6, TZ1, TZ262 and the No.1 slope break belt in the southeastern part (Fig. 9). For the $1^{\text {st }}$ upper submember of the Silurian Kepingtage Formation, the high-value areas of porosity and permeability are located in the vast area between well TZ10 and well TZ16 (Fig. 10). The highvalue areas of porosity and permeability of the $3^{\text {rd }}$ upper submember are also mainly distributed near the No.1 slope break belt between well TZ63 and well TZ30 in the southeastern part of the Tazhong area (Fig. 11).

The distribution characteristics of porosity and permeability of Carboniferous and Silurian reservoirs in the Tazhong area are closely related to the shallow water body in the southeastern part, relatively high structural position and shallow burial depth. Because the reservoir properties control hydrocarbon distribution, the exploration direction of the Carboniferous and Silurian clastic rocks in the Tazhong area should be the southeastern part. 


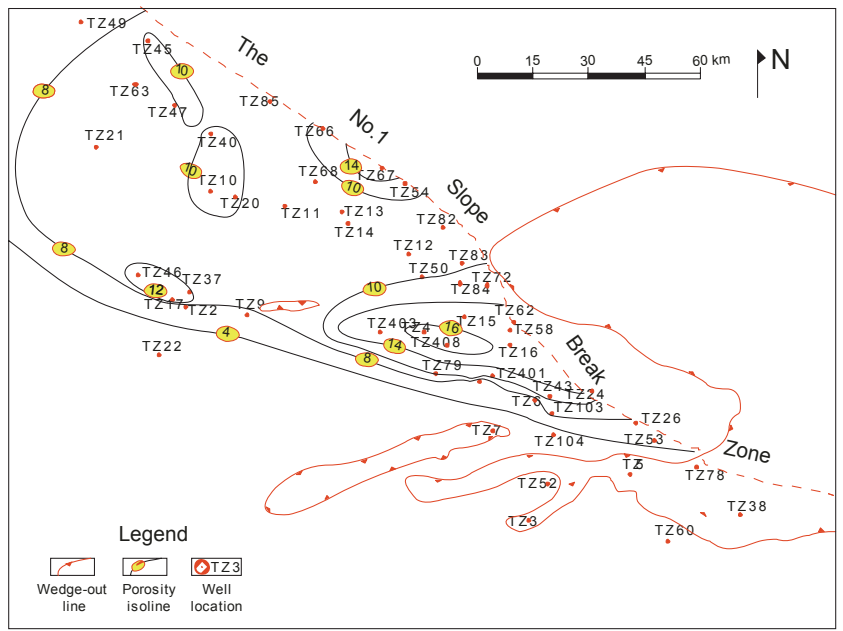

(a) Porosity

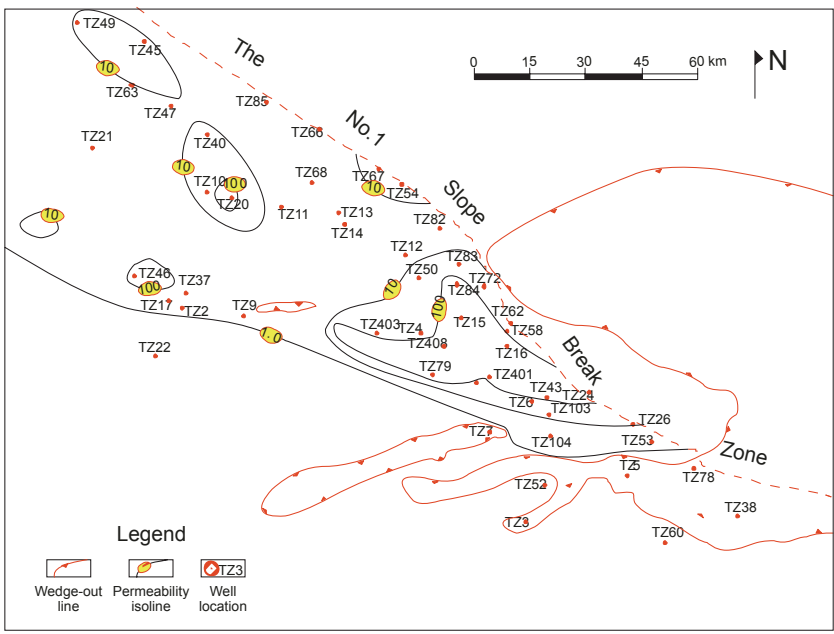

(b) Permeability

Fig. 9 Porosity (a) and permeability (b) distribution of the Carboniferous Donghe sandstone in the Tazhong area, Tarim Basin

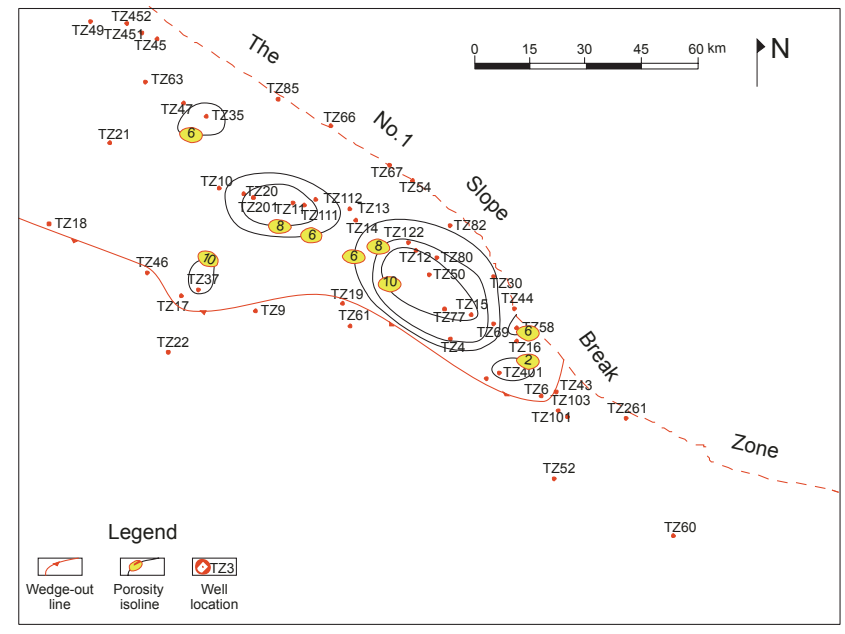

(a) Porosity

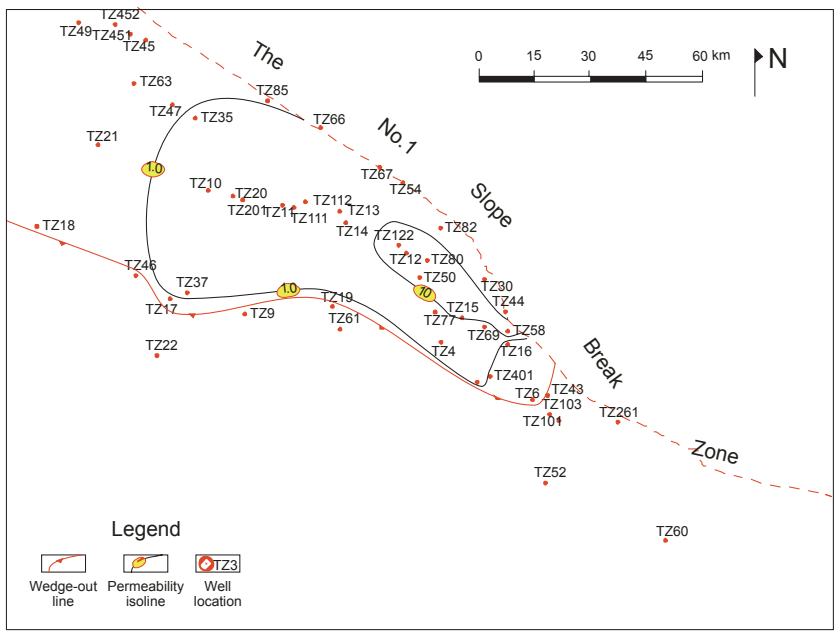

(b) Permeability

Fig. 10 Porosity (a) and permeability (b) distribution of the $1^{\text {st }}$ upper submember of the Silurian Kepingtage Formation in the Tazhong area, Tarim Basin

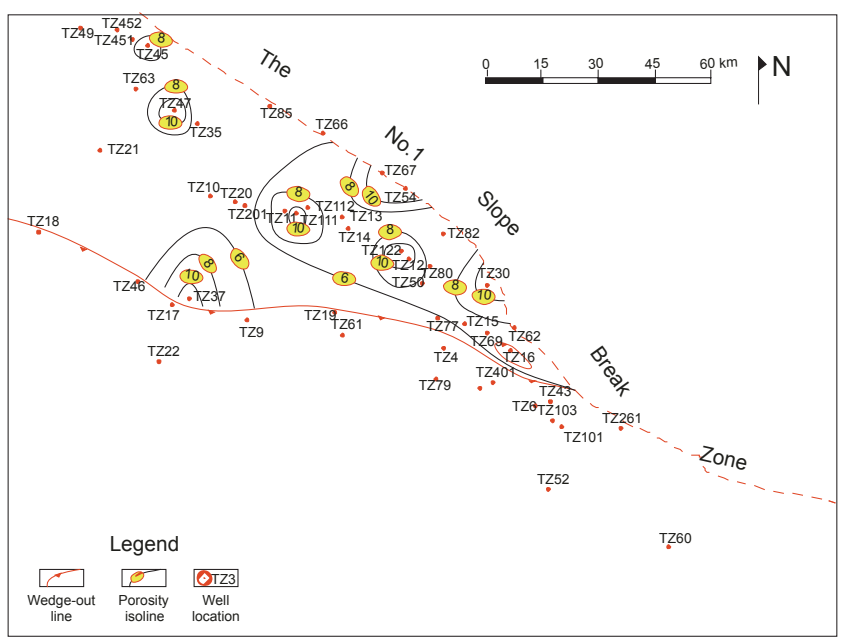

(a) Porosity

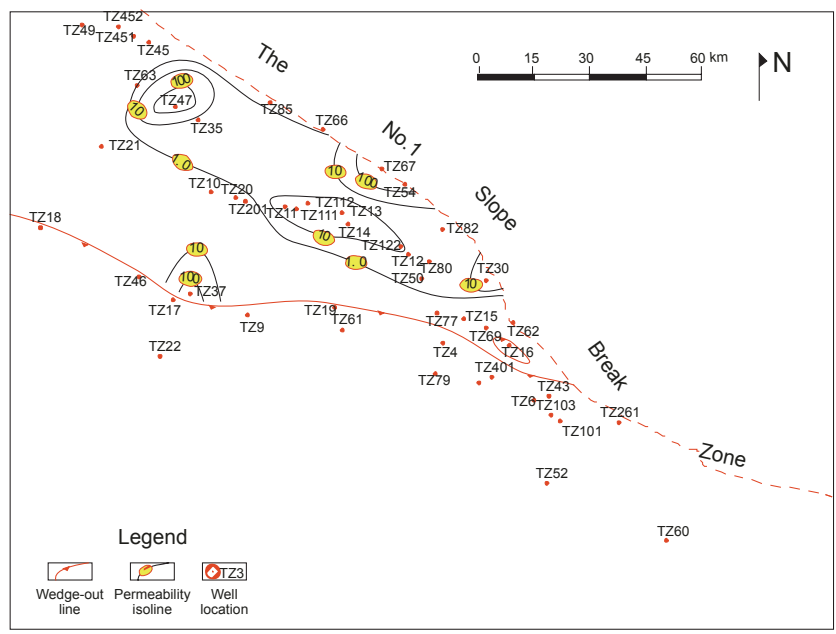

(b) Permeability

Fig. 11 Porosity (a) and permeability (b) distribution of the $3^{\text {rd }}$ upper submember of the Silurian Kepingtage Formation in the Tazhong area, Tarim Basin 


\section{The content of cement (especially carbonate cement) is the main factor controlling the porosity and permeability of clastic reservoirs}

The statistics of the interstitial material contents from many wells in the east and west of the Tazhong area show that the cement is the major interstitial material influencing the porosity and permeability of the Carboniferous Donghe sandstone reservoirs, especially the carbonate cement (Fig. 12). It can be seen from Fig. 12 that, the higher the interstitial material content, the lower the porosity, and vice versa. When the cement content is less than $5 \%$, the porosity is generally greater than $12 \%$. When the cement content is greater than $5 \%$, the porosity is generally less than $12 \%$. The main type of cement is carbonate, accounting for $92 \%$ of the total content (Fig. 13), being mainly calcite, ferrous calcite, dolomite and ankerite. Through the comparison between interstitial material content and porosity and permeability values of Donghe sandstone reservoirs from wells TZ40 and TZ75, it was found that there was a good correlation, and the layer with low interstitial material content especially low cement content had high values of porosity and permeability (Fig. 14). For example, the cement content of Donghe sandstone reservoir below 3,716 m from well TZ75 decreased, while the porosity and permeability increased significantly. When the cement content above 3,716 m increased, the reservoir properties became poor.

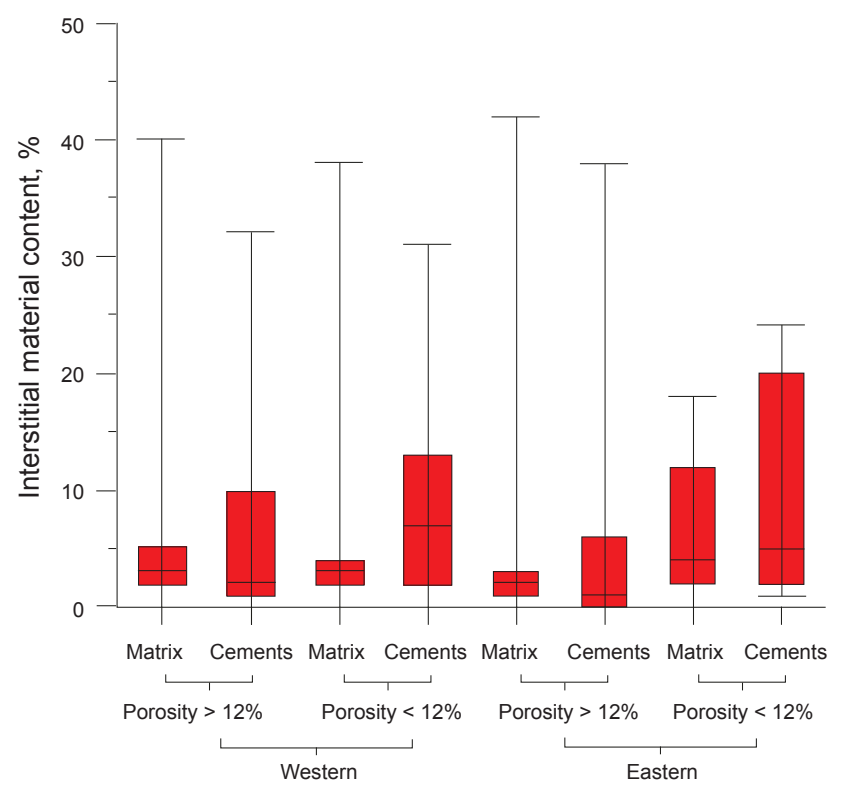

Fig. 12 Interstitial material contents of the Carboniferous Donghe sandstone reservoir in the Tazhong area, Tarim Basin

Similar to the Carboniferous clastic reservoir, the main cement of the Silurian reservoir is also carbonate cement (Figs. 15 and 16). The contents of carbonate cement of the $1^{\text {st }}$ and $3^{\text {rd }}$ upper submembers are $95 \%$ and $89 \%$, respectively, and the cements are mainly calcite, ferrous calcite, dolomite and ankerite. The cement content of the $3^{\text {rd }}$ upper submember is less than that of the $1^{\text {st }}$ upper submember, which is also

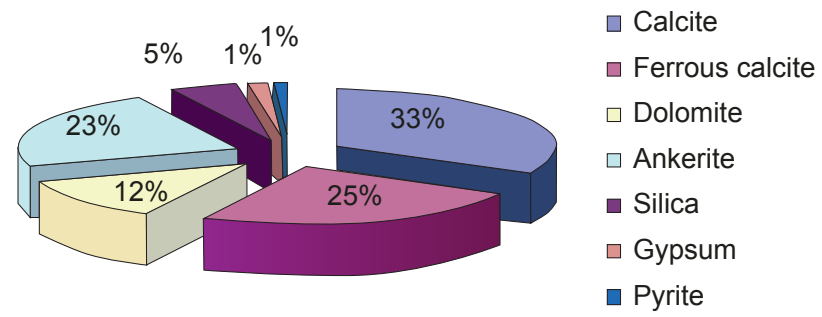

Fig. 13 Cement contents of the Carboniferous Donghe sandstone reservoir in the Tazhong area, Tarim Basin

an important reason why the former has better reservoir properties than the latter. The contents of interstitial material and cement of the $3^{\text {rd }}$ upper submember are less than those of the $1^{\text {st }}$ upper submember, but the matrix contents of them are similar (Fig. 17). So the differences between the two submembers are mainly caused by carbonate cement and are not related with the matrix content. There is a negative correlation between the interstitial material content and the porosity and permeability. With the increase of interstitial material content, the porosity and permeability of the reservoir decreased in general. The negative correlation also exists between the carbonate content and the porosity and permeability, which indicates that the carbonate cementation plays a leading role in the diagenetic cementation of the Silurian reservoirs in the study area (Fig. 18).

Through the discussion above, we believe that the cement content (especially carbonate cement content) is the main factor controlling the porosity and permeability of clastic reservoirs in this area. The differences between the Silurian and Carboniferous clastic reservoirs are related with the compositional maturity.

\section{The hydrocarbon distribution of Carboniferous and Silurian clastic reservoirs in the Tazhong area is closely related to the reservoir properties}

The reservoir is one of the most basic conditions to form hydrocarbon accumulations and the pores in the reservoir provide the space to store oil and gas. Therefore, the size and connectivity of the pores directly influence the accumulation and distribution of oil and gas (Wang, 2001; Cai, 2005; Yu et al, 2005; Wang et al, 2008; Liu et al, 1996). In order to search for the relationship between hydrocarbon distribution of Carboniferous and Silurian clastic reservoirs and the porosity and permeability, we plotted matching maps between the porosity and permeability and hydrocarbon distribution of the $3^{\text {rd }}$ upper submember of the Silurian Kepingtage Formation and Carboniferous Donghe sandstone (Figs. 19 and 20). It can be found that the Carboniferous Donghe sandstone reservoirs have been discovered in the area where the porosity of reservoir is high, which is more than $8 \%$. For instance, most of the reservoirs in the TZ4-TZ1, TZ16 and TZ24 well blocks in the southeast and the TZ47, TZ40 and TZ10 well blocks in the northwest are located in the area with the porosity more than $10 \%$ (Fig. 19), that is, the high-value areas of porosity control the hydrocarbon distribution. For clastic reservoirs, 


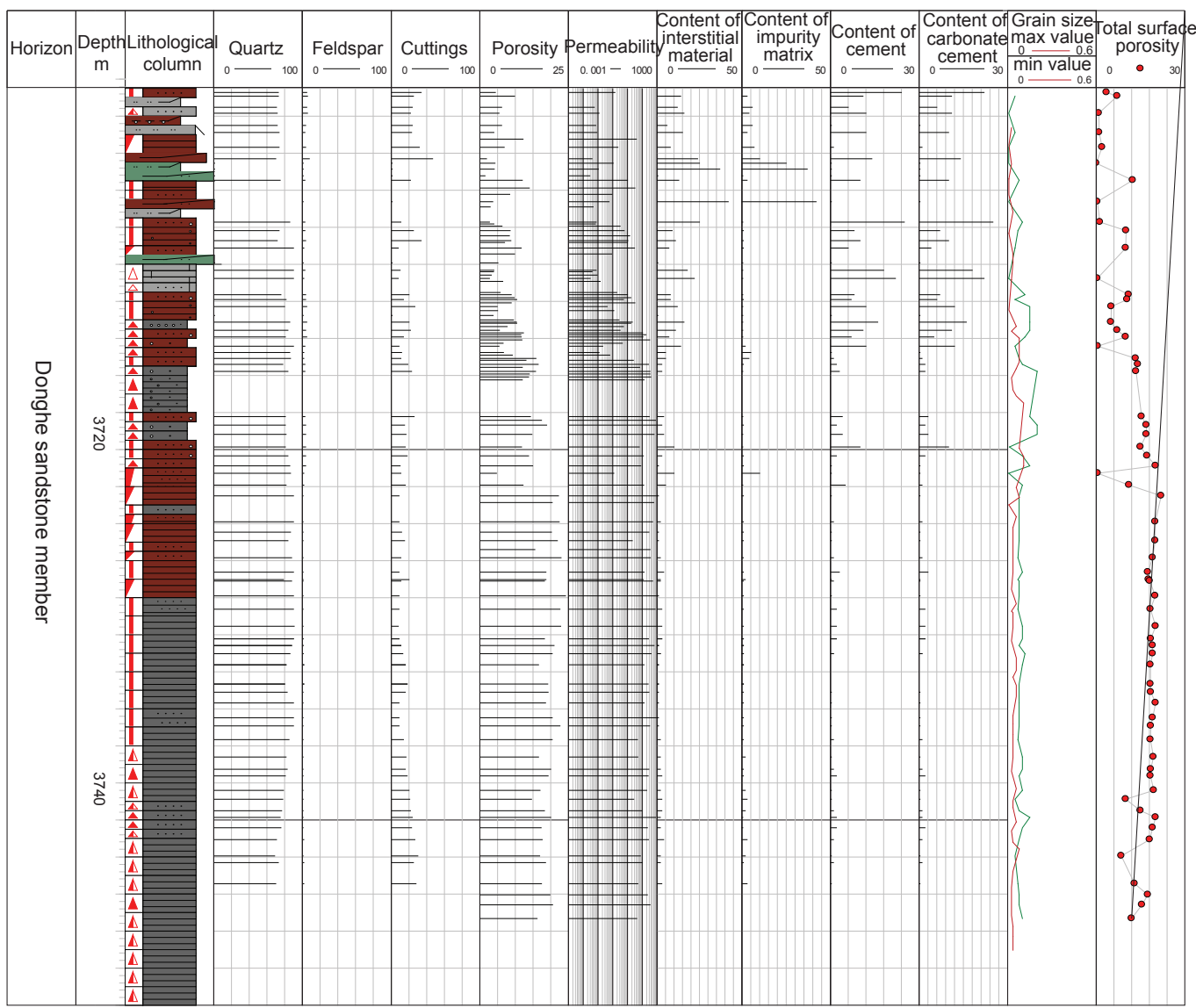

Fig. 14 Relationship between interstitial material content and porosity and permeability of the Carboniferous Donghe sandstone reservoir at well TZ75 in the Tazhong area, Tarim Basin

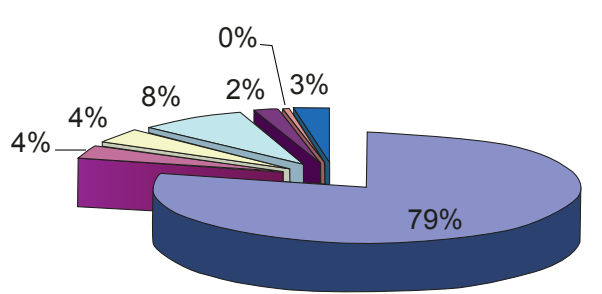
$\square$ Calcite
$\square$ Ferrous calcite
$\square$ Dolomite
$\square$ Ankerite
- Silica
$\square$ Gypsum
- Pyrite

Fig. 15 Cement content of the Silurian $1^{\text {st }}$ upper submember reservoir in the Tazhong area, Tarim Basin

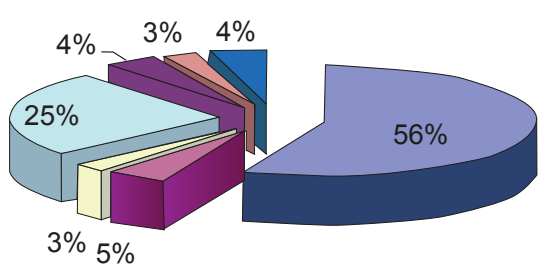

\section{$\square$ Calcite \\ $\square$ Ferrous calcite \\ $\square$ Dolomite \\ $\square$ Ankerite \\ - Silica \\ $\square$ Gypsum \\ a Pyrite}

Fig. 16 Cement content of the Silurian $3^{\text {rd }}$ upper submember reservoir in the Tazhong area, Tarim Basin

such a correlation between hydrocarbon distribution and permeability also exists in these areas.

At present, there are four Silurian reservoirs including TZ47, TZ11, TZ12-TZ50 and TZ16 in the Tazhong area,

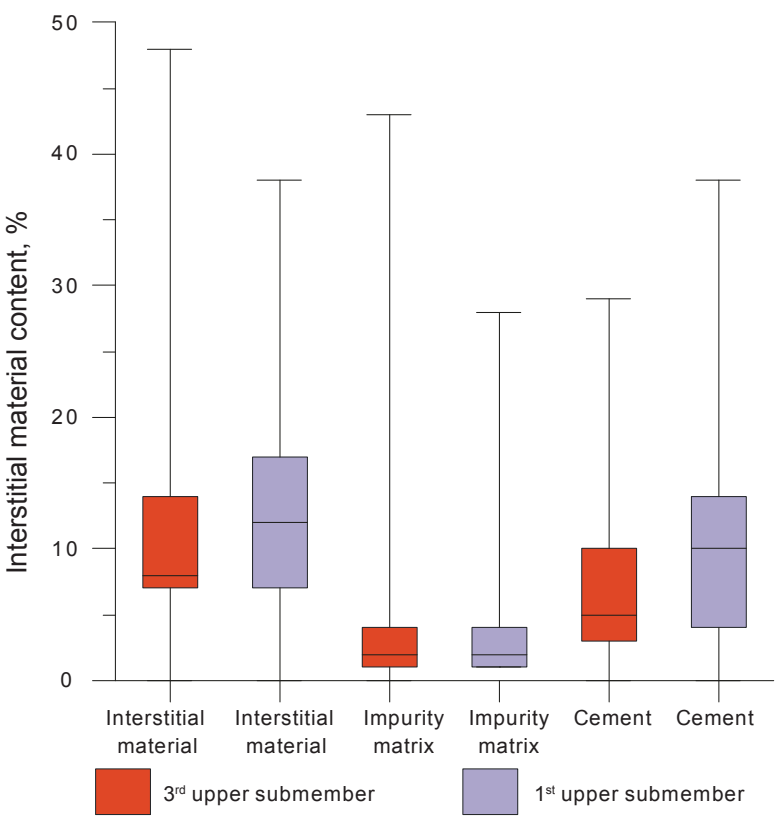

Fig. 17 Interstitial material content of the Silurian reservoir in the Tazhong area, Tarim Basin

and they are mainly in the $3^{\text {rd }}$ upper submember (Fig. 20). Similar to the distribution of Carboniferous Donghe sandstone reservoirs, the Silurian reservoirs are all located in the high-value areas of porosity of the $3^{\text {rd }}$ upper submember 


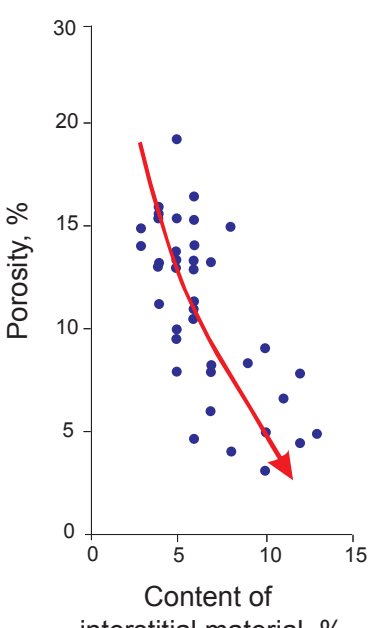

interstitial material, \%

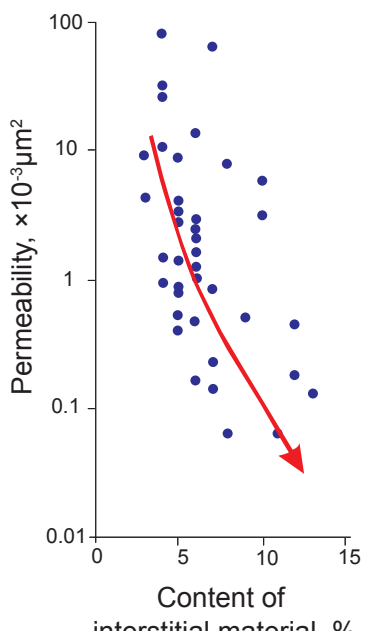

interstitial material, \%

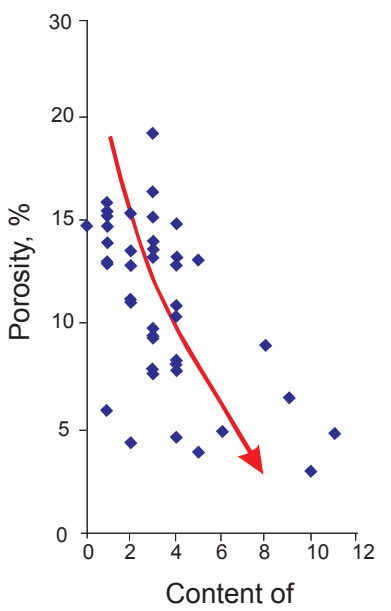

carbonate cement, \%

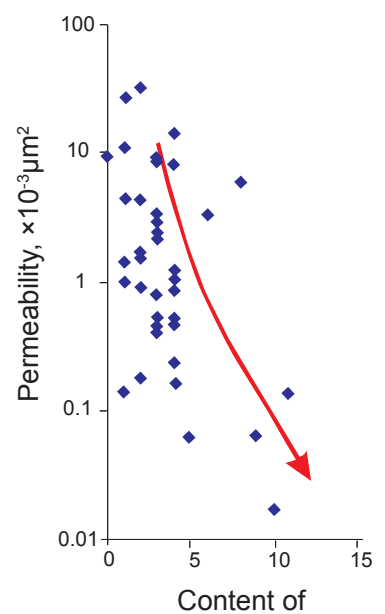

carbonate cement, \%

Fig. 18 Relationship between reservoir properties and interstitial material or carbonate cement content of the Silurian $3^{\text {rd }}$ upper submember at well TZ111 in the Tazhong area, Tarim Basin

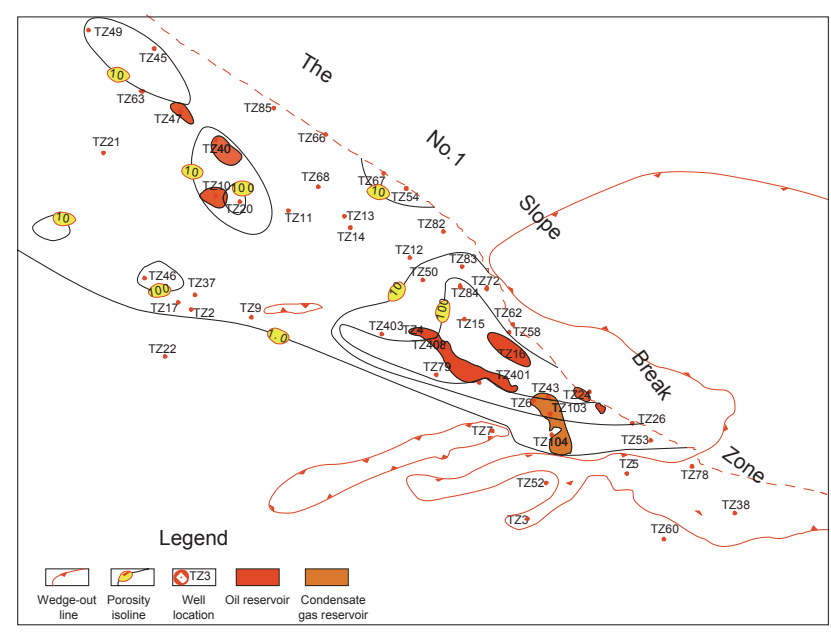

Fig. 19 Matching map between porosity and distribution of the Carboniferous Donghe sandstone reservoirs in the Tazhong area, Tarim Basin

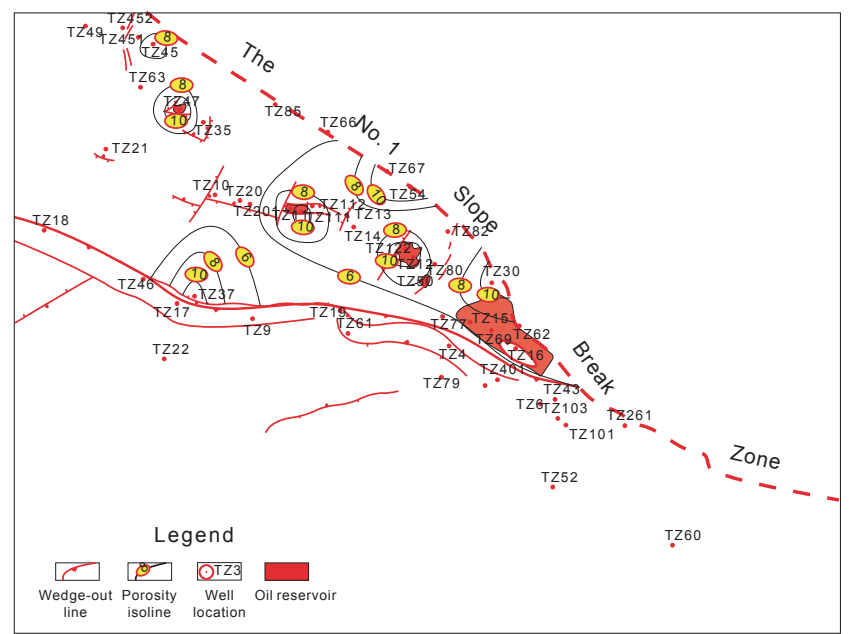

Fig. 20 Matching map between porosity and distribution of the $3^{\text {rd }}$ upper submember reservoir of the Silurian Kepingtage Formation in the Tazhong area, Tarim Basin with the porosity greater than $8 \%$ (Fig. 20). Because of the relationship between reservoir distribution and high-value areas of porosity, it can be considered that the distribution of clastic reservoirs in the study area is closely related to the properties of reservoirs.

\section{Prediction of favorable hydrocarbon exploration targets of Paleozoic clastic reservoirs in the Tazhong area}

The high-value areas of the properties of Carboniferous and Silurian clastic reservoirs are located in the southeast of the Tazhong area. The main factor controlling the properties of clastic reservoirs is the cement content (especially the carbonate cement content). The hydrocarbon distribution of the Carboniferous and Silurian is closely related to the reservoir properties and is generally in the high-value areas of porosity and permeability. In other words, the basis for predicting favorable hydrocarbon exploration areas is the porosity and permeability of reservoirs. Therefore, the hydrocarbon exploration of the two sets of strata should be focused on the southeast of the Tazhong area, especially on the updip pinch-out area. However, due to the local sedimentation or the post-depositional reconstruction, the clastic reservoirs of the two sets of strata can also form highvalue areas of porosity and permeability in the middle of the Tazhong area, which should also be considered as favorable exploration areas, such as the Donghe sandstone reservoir in the TZ66-TZ54 well block near the No.1 slope break zone in the northern part of the middle Tazhong area (the porosity values are higher than 10\%) and the TZ46-TZ37 well block in the southern part (the porosity values are higher than $12 \%$ ). For the $3^{\text {rd }}$ upper submember of the Silurian Kepingtage Formation, the TZ67-TZ54 well block near the No.1 slope break zone in the northern part of the middle Tazhong area, the TZ17-TZ37 well block in the southern part, and the TZ83-TZ44 well block in the southeastern part, with porosity 
values more than $10 \%$, should be regarded as favorable areas. In fact, the TZ66-TZ54 well block of the Carboniferous and the TZ67-TZ54 well block of the Silurian are overlapped with each other, so are the TZ46-TZ37 and TZ17-TZ37 well blocks. Therefore, we should strengthen the exploration in the two areas, expecting to find Carboniferous and Silurian reservoirs. However, the above prediction is based on the reservoir characteristics. In order to obtain more objective understanding, research on hydrocarbon accumulation and preservation conditions should also be carried out.

\section{Conclusions}

1) The Donghe sandstone mainly consists of lithic quartz sandstone, and the compositional maturity is high. Generally, the porosity is $3 \%-20 \%$ and the permeability is $0.1 \times 10^{-3} \mu \mathrm{m}^{2}$ $500 \times 10^{-3} \mathrm{\mu m}^{2}$, and there is a relatively good linear relationship between porosity and permeability. The main pore types are residual primary intergranular pores and intergranular dissolved pores. The $1^{\text {st }}$ and $3^{\text {rd }}$ upper submembers consist mainly of lithic sandstone. The porosity and permeability values are mostly in the range of $0-9 \%$ and $0-2 \times 10^{-3} \mu \mathrm{m}^{2}$, respectively, and a relatively good linear relationship between porosity and permeability also exists. The cement content is the main factor controlling the reservoir properties. The higher the interstitial material content, the lower the porosity, and vice versa. The Carboniferous Donghe sandstone reservoirs are better than the Silurian reservoirs on the whole.

2) The high-value areas of porosity and permeability of clastic reservoirs are located in the southeast of the Tazhong area. This distribution characteristic is closely related to the shallow water deposits in the southeastern part, relatively high structural position and shallow burial depth. Because the reservoir properties control hydrocarbon distribution, exploration of the Carboniferous and Silurian clastic rocks in the Tazhong area should be directed at the southeastern part.

3) The discovered Paleozoic reservoirs in the Tazhong area have a good matching relationship with the high-value areas of porosity, and are located in the area with the porosity more than $8 \%$. The basis for predicting favorable hydrocarbon exploration areas is the porosity and permeability of reservoirs. Therefore, the hydrocarbon exploration of the two sets of strata should be focused on the southeast of the Tazhong area, especially on the updip pinch-out area.

\section{Acknowledgements}

This work is supported by the Basic Research Program of China (973 Program, Grant No. 2006CB202308).

\section{References}

Cai X Y. Reservoiring conditions and exploration targets in Tarim Basin. Oil \& Gas Geology. 2005. 26(5): 590-597 (in Chinese)

Chen J S, Wang Z Y, Dai Z Y, et al. Study of the middle and upper Ordovician rimmed carbonate platform system in the Tazhong area, Tarim Basin. Journal of Palaeogeography. 1999. 1(2): 8-17 (in Chinese)

Dai Z Y, Zhou Y, Chen J S, et al. The characteristics and evaluation of middle \& upper Ordovician reef \& shoal related carbonate reservoir in Tazhong North Slope, Tarim Basin. Journal of Southwest
Petroleum University. 2001. 23(4): 1-5 (in Chinese)

Gu J Y. Sedimentary environment and reservoir characters of the Carboniferous Donghe sandstone in the Tarim Basin. Acta Geologica Sinica. 1996. 70(2): 153-161 (in Chinese)

Gu J Y, Zhang X Y and Guo B C. Characteristics of sedimentation and reservoir of the Donghe sandstone in Tarim Basin and their synthetic analysis. Journal of Palaeogeography. 2006. 8(3): 285-294 (in Chinese)

Jia J H, Zhang B M, Zhu S H, et al. Stratigraphy, sedimentary characteristics and lithofacies palaeogeography of the Silurian in Tarim Basin. Journal of Palaeogeography. 2006. 8(3): 339-351 (in Chinese)

Li Y P, Li X S, Zhou Y, et al. Sedimentary characteristics and evolution history of middle-upper Ordovician in Tazhong area. Xinjiang Petroleum Geology. 2000. 21(3): 133-137 (in Chinese)

Liu J D, Zhang S N, Tian J C, et al. Discussion on exploration direction and depositional system of Silurian-Devonian in Tarim Basin, China. Journal of Chengdu University of Technology (Science \& Technology Edition). 2004. 31(6): 654-657 (in Chinese)

Liu L F, Li Y, Wang P, et al. Reservoir types and favorable oil-gas exploration zone prediction of the upper Ordovician Lianglitage Formation in Tazhong No.1 fault belt of Tarim Basin. Journal of Palaeogeography. 2008. 10(3): 221-230 (in Chinese)

Liu S G, Zhai Y H and Guo J H. Pore texture and evaluation of Carboniferous clastic reservoirs in Tazhong area. Journal of Oil and Gas Technology. 1995. 17(3): 8-12 (in Chinese)

Liu S P, Zhong G F, Liu X F, et al. Characteristics and evaluation of Silurian sandstone reservoir in Tazhong area, Tarim Basin. Journal of Oil and Gas Technology. 1996. 18(4): 21-25 (in Chinese)

Shen A J, Wang Z M, Yang H J, et al. Genesis classification and characteristics of Ordovician carbonate reservoirs and petroleum exploration potential in Tazhong region, Tarim Basin. Marine Origin Petroleum Geology. 2006. 11(4): 1-12 (in Chinese)

Sun L D, Zhou X Y and Wang G L. Contributions of petroleum geology and main directions of oil-gas exploration in the Tarim Basin. Chinese Journal of Geology (Scientia Geologica Sinica). 2005. 40(2): 167-178 (in Chinese)

Wang G C. Characteristics of clastic reservoirs in the Tarim Basin. Petroleum Geology \& Experiment. 2001. 23(1): $62-66$ (in Chinese)

Wang P, Liu L F, Li Y, et al. Reservoir characteristics of the 3rd upper sub-member of the Silurian Kepingtage Formation in Tazhong area and their relations to oil and gas distribution. Oil \& Gas Geology. 2008. 29(2): 174-180 (in Chinese)

Wang S M and Lü X X. Features and petroleum significance of Ordovician carbonate reservoir in Tazhong area, Tarim Basin. Journal of Xi'an Shiyou University (Natural Science Edition). 2004. 19(4): $72-76$ (in Chinese)

Wu C J, Dai Z Y and Liu S H. Study on the physical factors of Carboniferous Donghe sandstone reservoir in Tazhong area. Contributions to Geology and Mineral Resources Research. 2006. 21(3): 199-202 (in Chinese)

Yu R L, Yan X B, Jin X H, et al. Research achievements and exploration direction in Tarim Basin. Oil \& Gas Geology. 2005. 26(5): 598-604 (in Chinese)

Zhong D K, Zhu X M, Zhou X Y, et al. Effect of structure on sandstone's porosity evolution: a case study from the Donghe sandstones in central Tarim. Chinese Journal of Geology (Scientia Geologica Sinica). 2004. 39(2): 214-222 (in Chinese)

Zhu X M, Zhang Q, Zhao C L, et al. Sedimentary facies and environmental changes of the Donghe sandstone in central Tarim. Chinese Journal of Geology (Scientia Geologica Sinica). 2004. 39(1): 27-35 (in Chinese) 